\title{
ARTIGOS
}

\section{ALTERAÇÕES QUANTITATIVAS DAS CÉLULAS NEUROENDÓCRINAS NO MEGACÓLON CHAGÁSICO*}

\author{
Alfredo J.A. Barbosa, Nivaldo H. Toppa, José R. Cunha Melo e Washington L. Tafuri
}

\begin{abstract}
Utilizando-se técnicas histoquimicas pela prata (Masson-Fontana e SevierMunger) estudaram-se a distribuiçâo e o número de células enterocromafins (EC) e do conjunto EC mais células argirófilas (ARG) em peças cirúrgicas de megassigmóide chagásico. Observou-se que tanto nos "megas" $(n=16)$ como nos controles $(n=8), a$ posição das células EC e ARG na mucosa foi predominantemente basal, com distribuição irregular, principalmente das EC. A análise histológica revelou aparente aumento numérico das EC e do conjunto EC mais ARG. Todavia, contagens sistematizadas mostraram que somente o conjunto dessas células apresentou aumento estatisticamente significativo $(P<0,01)$. Realizou-se também o estudo morfométrico da mucosa e das musculares que revelou espessamento significativo $(P<0,01)$ dessas camadas em relação aos casos controles.
\end{abstract}

Palavras Chaves: Megacólon chagásico. Células enterocromafins. Células argirófilas. Células neuroendócrinas.

As células endócrinas constituem importante componente da mucosa digestiva e se distribuem desde as glândulas cárdicas até o ânus ${ }^{12} 3233$. Através de métodos imunocitoquimicos muitos peptídeos já foram identificados nestas células sendo que um grande número delas produz tambem 5-hidroxitriptamina (5-HT). No instestino, elas se localizam principalmente na região profunda da mucosa. repousando sobre a membrana basal das glândulas. A maioria delas atinge a luz glandular através de prolongamento da região apical do citoplasma que funcionaria como um pólo receptor de estimulos, tendo sido chamadas células "receptoras-secretoras" ou seja, capazes de receber o estímulo pelo ápice e liberar a secreçào pela base ${ }^{15}$. Embora muitos dos peptideos secretados por estas células sejam lançados na corrente circulatória atuando à đístância (efeito hormonal) outras células endócrinas produzem substâncias com ação predominantemente local 24 (efeito parácrino) e que podem ser encontradas também no sistema nervoso central e periférico. Essa dualidade da presença de peptideos e aminas biogènicas, tanto em células endocrinas como em terminaçōes nervosas, e a constatação de ações dessas substâncias sobre as funçoes secretoras e peristálticas do sistema digestivo, deu origem à hipótese cada vez mais aceita de que atuariam no processo de neurotransmissão através de um hipotético mecanismo modulatório 10131623 .

\footnotetext{
* Trabalho realizado no Departamento de Anatomia Patológica e Medicina Legal da Faculdade de Medicina da Universidade Federal de Minas Gerais. Av. Alfredo Balena $190,30.000$, Belo Horizonte, MG. Brasil.

Auxilio financeiro: CNPq (Proc. no $30.1851 / 76$ ) e FINEP (Proc. no 43/83/01 19/00).
}

Recebido para publicaçào em $7 / 12 / 84$
No megacólon chagásico ocorrem lesòes ao nivel do sistema nervoso intramural 2136 acarretando graves disturbios do peristaltismo. Long e $\operatorname{cols}^{26}$ estudando biópsias retais de chagásicos crônicos encontraram depleção tecidual de peptideo intestinal vasoativo (VIP), substância $P$ (SP), somatostatina (SOM) e enteroglucagon (EG). Através da imunofluorescència indireta verificaram escassez de células $\mathrm{D}$, produtoras de SOM, e de L, produtoras de EG, o que estaria de acordo com a depleção desses peptídeos extraidos da parede. Por outro lado, Lindop 25 estudando um caso de megacolon idiopático relatou hiperplasia de células enterocromafins (EC) e, entre outras possibilidades, admitiu que poderia ser uma resposta às alterações da parede do órgão.

Tendo em vista, portanto, as possiveis interrelaçôes fisiológicas das células endócrinas com a inervação intramural do intestino propós-se estudar a população de células EC e argirófilas (ARG) e, ao mesmo tempo, proceder às medidas das dimensòes da mucosa e musculares em peças cirúrgicas de megacólon chagásico.

\section{MATERIAL E MÉTODO}

Utilizaram-se 8 casos controles de pacientes portadores de adenocarcinoma do reto e 16 megacólons de pacientes chagásicos crônicos, MachadoGuerreiro positivos, que se submeteram à cirurgia no Hospital das Clínicas da UFMG, Belo Horizonte. As peças cirúrgicas foram abertas pela borda mesenterica, lavadas em água corrente retirando-se 3 a 5 fragmentos da região sigmóidea em áreas onde a parede e a mucosa apresentavam-se sem sinais de compressão ou outras lesões evidentes. Os fragmentos retirados foram fixados em formol a $10 \%$ durante $24-48$ horas. Posteriormente, foram desidratados, diafanizados e 
incluídos em parafina como de rotina. Dois blocos de cada caso foram selecionados para estudo, tendo sido obtidos cortes escalonados de $5 \mu \mathrm{m}$ de espessura. Procederam-se às seguintes colorações, além da Hematoxilina e Eosina (H-E): (a) reação argentafim de Masson-Fontana 1427 modificando-se entretanto a concentração de nitrato de prata para $0,5 \mathrm{~g} \% \mathrm{e}$, para $60^{\circ} \mathrm{C}$, a temperatura de incubação ${ }^{3} ;($ b) coloração do conjunto de células EC + ARG pelo método de Sevier-Munger ${ }^{30}$. As lâminas coradas pelo $\mathrm{HE}$ foram utilizadas para o estudo morfométrico da mucosa e das musculares, ou seja: (a) medida do "comprimento das criptas" o que se considerou como sendo a distância compreendida entre a base das glândulas, no limite interno da muscular da mucosa e o epitélio superficial de revestimento da mucosa, $e(b)$, medida da espessura das camadas musculares principais e da muscular da mucosa. Estas medidas foram realizadas em 3 a 4 áreas selecionadas nos 2 diferentes fragmentos de cada caso, obtendo-se em seguida a média aritmética das medidas. Para a utilização dessas medidas, utilizou-se o microscópio binocular Wild Leitz sendo uma das oculares. substituida por ocular ZEISS $(12,5 \mathrm{x})$ provida com escala reticulada móvel e disco micrométrico com 100 divisões. A ampliação do campo foi de 50x. Nestas condições, cada divisão do disco micrométrico era equivalente a $5,6 \mu \mathrm{m}$ o que foi padronizado utilizando-se lâmina micrometrada.

As contagens das células EC e do conjunto $\mathrm{EC}+\mathrm{ARG}$ foram realizadas no mesmo microscópio binocular com ampliação de 400x, contando-se o número de células por campo microscópico e por cripta. Para a primeira contagem, considerou-se apenas a metade basal aproximada da mucosa correndo-se o campo microscópico (diâmetro do campo: $450 \mathrm{\mu m}$ ) a partir da superficie interna da muscular da mucosa. Em cada caso contaram-se 10 campos consecutivos. Quando apenas um corte não era suficiente utilizaram-se outros cortes. Para as contagens de células por cripta contaram-se o número total de células em toda a extensão da parede de 20 criptas consecutivas (da base da cripta ao epitélio superficial) considerando-se consecutivas as criptas cortadas longitudinalmente ao longo de toda sua extensão e encontradas sucessivamente em um ou mais cortes.

\section{RESULTADOS}

A análise das preparações coradas pela H.E. mostrou os cólons-controle sem alteraçōes histológicas relevantes. Nos megacólons observaram-se: (a) aumento da espessura da parede, bem evidente na maioria dos casos; (b) presença de infiltrado inflamatório, predominantemente linfocitário, focal, ora na intimidade das camadas musculares, ora na região do plexo mioentérico, ou seja, em torno da rede nervosa, dos glânglios ou no interior destes (miosite focal, periganglionite e ganglionite); (c) fibrose de distribuição predominantemente focal das camadas musculares e ou da região do plexo mioentérico. As alterações descritas em (a), (b) e (c) eram de intensidade variável, às vezes relativamente intensas, às vezes discretas. $\mathrm{Na}$ lâmina própria da mucosa, em alguns casos dos controles e dos "megas", observou-se moderado infiltrado de células mononucleadas.

A espessura média da camada muscular principal nos megacólons foi significativamente superior $(\mathrm{P}<0,01)$ que a dos controles $(1325 \mu \mathrm{m}$ vs. 945 $\mu \mathrm{m})$. A muscular da mucosa foi também significativamente $(P<0,01)$ mais espessa nos megacólons (86 $\mu \mathrm{m}$ vs. $33 \mu \mathrm{m}$ ). O comprimento médio das criptas nos megacólons foi de $1064 \mu \mathrm{m}$ e nos controles, $604 \mu \mathrm{m}$ (Fig. 1); a diferença das médias foi altamente significativa $(\mathbf{P}<0,01)$. Os resultados do estudo morfométrico podem ser vistos na Tabela 1.

As células endócrinas coradas pelos dois métodos utilizados foram bem evidentes nas preparações tornando-se negras ou marrom-escuras sobre um fundo marrom-claro (Fig. 2). Tanto as células EC como o conjunto EC + ARG foram muito mais freqüentes na porção basal da mucosa e apenas algumas poucas foram encontradas no terço superficial da mucosa. O exame histológico das preparaçōes mostrou, nos megacólons, aparente aumento numérico das células EC e do conjunto EC + ARG (Fig. 2). Alem disso, observou-se que nos megacólons, as células apresentavam-se mais fortemente coradas, (Figs. 2, C e F), embora em algumas áreas, ou mesmo em alguns casos, essas diferenças eram menos notórias. As celulas EC, tanto nos controles como nos megacólons, apresentaram distribuição mais irregular na mucusa do que o conjunto de células coradas pelo método de Sevier-Munger.

Tabela 1 - Espessura da muscular própria, da muscular da mucosa e comprimento das criptas nos megacólons e controles, medidas (em $\mathrm{Mm}$ ) efetuadas em cortes histológicos corados pelo H.E. ( $* P<0,01)$.

\begin{tabular}{lccc}
\hline & Grupos & $\bar{X} \pm D . P$. & $\begin{array}{c}\text { Variação } \\
(\%)\end{array}$ \\
\hline $\begin{array}{l}\text { Espessura da } \\
\text { muscular } \\
\text { própria }\end{array}$ & $\begin{array}{c}\text { controles } \\
(\mathrm{n}=8) \\
\text { megacólon } \\
(\mathrm{n}=16)\end{array}$ & $945 \pm 196$ & $36,7^{*}$ \\
$\begin{array}{l}\text { Espessura da } \\
\text { muscular da } \\
\text { mucosa }\end{array}$ & $\begin{array}{c}\text { controles } \\
(\mathrm{n}=8) \\
\text { megacólon } \\
(\mathrm{n}=25)\end{array}$ & $33 \pm 10$ & \\
& $\begin{array}{c}\text { controles } \\
(\mathrm{n}=8)\end{array}$ & $604 \pm 120$ & $160,6^{*}$ \\
$\begin{array}{l}\text { Comprimento } \\
\text { das criptas }\end{array}$ & $\begin{array}{c}\text { megacólon } 1064 \pm 255 \\
(\mathrm{n}=13)\end{array}$ & $76,2 *$ \\
\hline
\end{tabular}

A população média de células EC por campo e por cripta nos controles e megacólons está expressa na Tabela 2. Embora ambas as médias nos megacólons fossem superiores em relação aos controles, respec- 
Barbosa AJA, Toppa NH, Melo JRC, Tafuri WL. Alterações quantitativas das células neuroendócrinas no megacólon chagásico. Revista da Sociedade Brasileira de Medicina Tropical 18: 215-221, Out-Dez, 1985

tivamente 11 vs. 6,5 e 3,1 vs. 2,4 , as diferenças não foram estatisticamente significativas $(P>0,05)$.

A população média do conjunto de células EC + ARG nos 2 grupos estudados está expressa na Tabela 3. Tanto a média das células contadas por campo, como a média das células contadas por cripta, foram significativamente maiores nos megacólons chagásicos em comparação com os controles $(\mathrm{P}<0,01)$.

Tabela 2 - Número médio de células enterocromafins $(E C)$ por campo microscópico (400x) da região basal da mucosa e ao longo de toda a extensão da cripta no megacólon chagásico $(n=16) \mathrm{e} \mathrm{em}$ colons controles $(n=8)$, regiāo sigmóidea. ${ }^{*} P>0,05$.

\begin{tabular}{lcrc}
\hline & Grupos & $\bar{X} \pm$ D.P. & $\begin{array}{c}\text { Variação } \\
(\%)\end{array}$ \\
\hline $\begin{array}{l}\text { Células EC } \\
\text { por campo }\end{array}$ & $\begin{array}{c}\text { Controles } \\
\text { Megacólons }\end{array}$ & $\begin{array}{r}6,5 \pm 3,5 \\
11,0 \pm 9,4\end{array}$ & $69,2 *$ \\
Células EC & Controles & $2,4 \pm 0,8$ & $29,2 *$ \\
por cripta & Megacólons & $3,1 \pm 1,1$ & 2, \\
\hline
\end{tabular}

\section{DISCUSSÃO}

Nas enteromegalias chagásicas além da dilatação da luz observa-se aumento da espessura da parede do órgão 22 . Esta observação anatomopatológica é

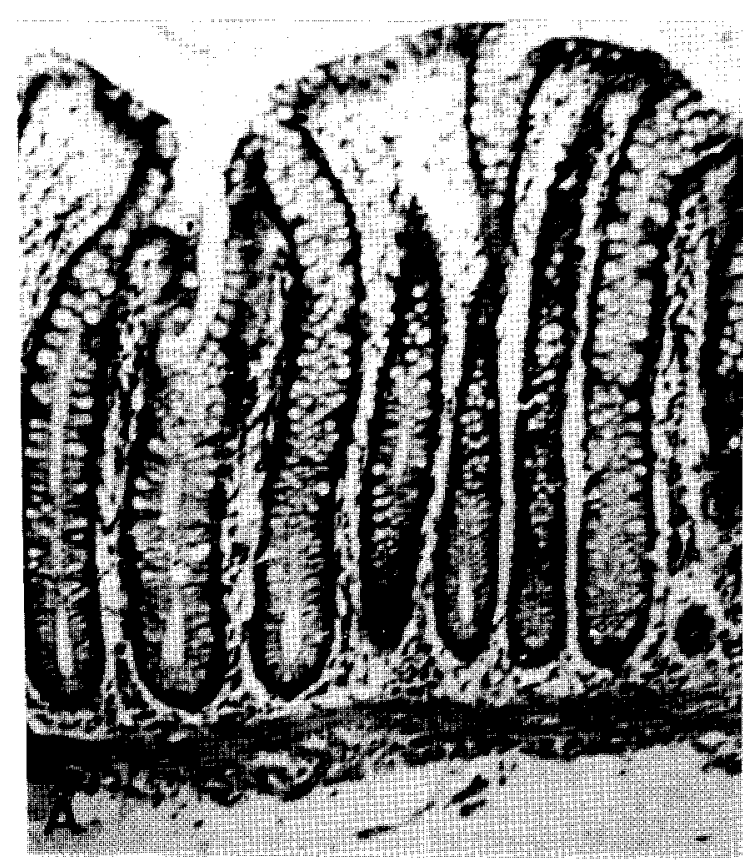

comum e pode ser constatada na maioria dos casos de megacólon; as exceções a esta regra ocorrem em virtude de fatores secundários que direta ou indiretamente provocam o adelgaçamento da parede do órgão, como processos inflamatórios localizados, ulcerações e compressões, estas últimas principalmente por fecaloma, o que resulta em isquemia e

Tabela 3-Número médio de células enterocromafins e argirófilas $(E C+A R G)$ por campo microscópico (400x) da região basal da mucosa e ao longo de toda a extensão da cripta, no megacólon chagásico $(n=16)$ e em cólons controles $(n=8)$, regiào sigmóidea. ${ }^{*} P<0,01$.

\begin{tabular}{lcrc}
\hline & Grupos & $\bar{X} \pm$ D.P. & $\begin{array}{c}\text { Variacão } \\
(\%)\end{array}$ \\
\hline $\begin{array}{l}\text { Células } \\
\text { EC + ARG }\end{array}$ & Controles & $7,7 \pm 4,6$ & $100 *$ \\
por campo & Megacólons & $15,4 \pm 6,1$ & \\
$\begin{array}{l}\text { Células } \\
\text { EC + ARG }\end{array}$ & Controles & $2,9 \pm 0,9$ & \\
por cripta & Megacólons & $5,0 \pm 1,8$ & \\
\hline
\end{tabular}

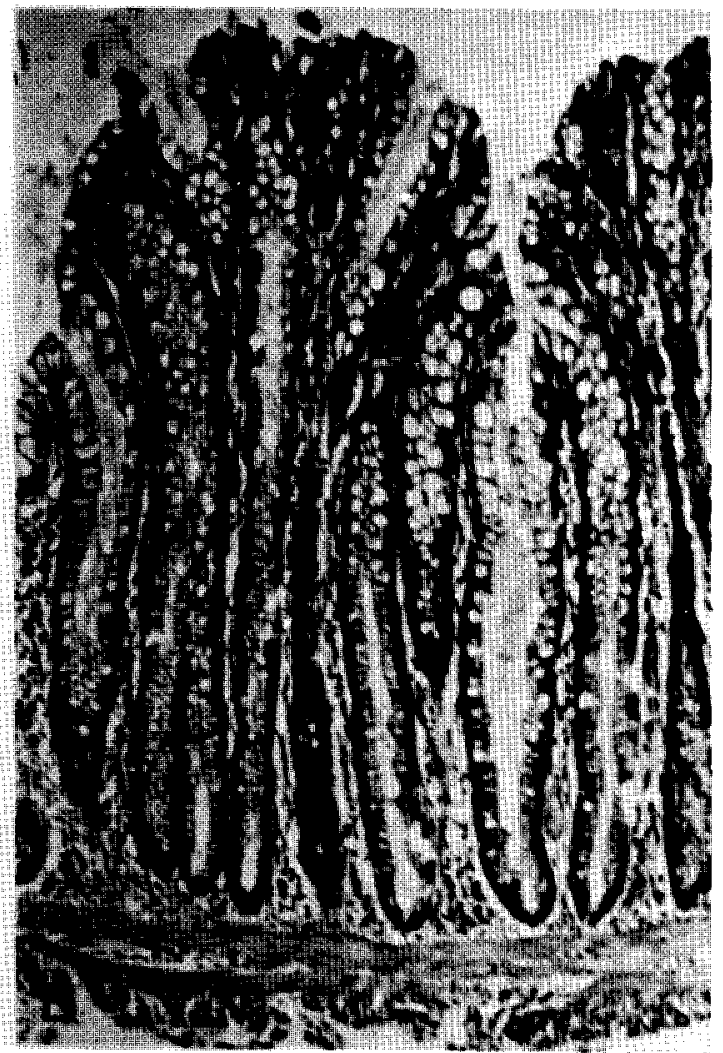

Figura 1-Microfotografias de mucosa de cólon controle (A) e de megacolon chagásico (B). Observar aumento da espessura da muscular da mucosa e da altura das criptas no megacolon (HE, $A$ e $B=80 x$, ampliação original). 
Barbosa AJA, Toppa NH, Melo JRC, Tafuri WL. Alterą̧ões quantitativas das células neuroendócrinas no megacólon chagásico. Revista da Sociedade Brasileira de Medicina Tropical 18: 215-221, Out-Dez, 1985

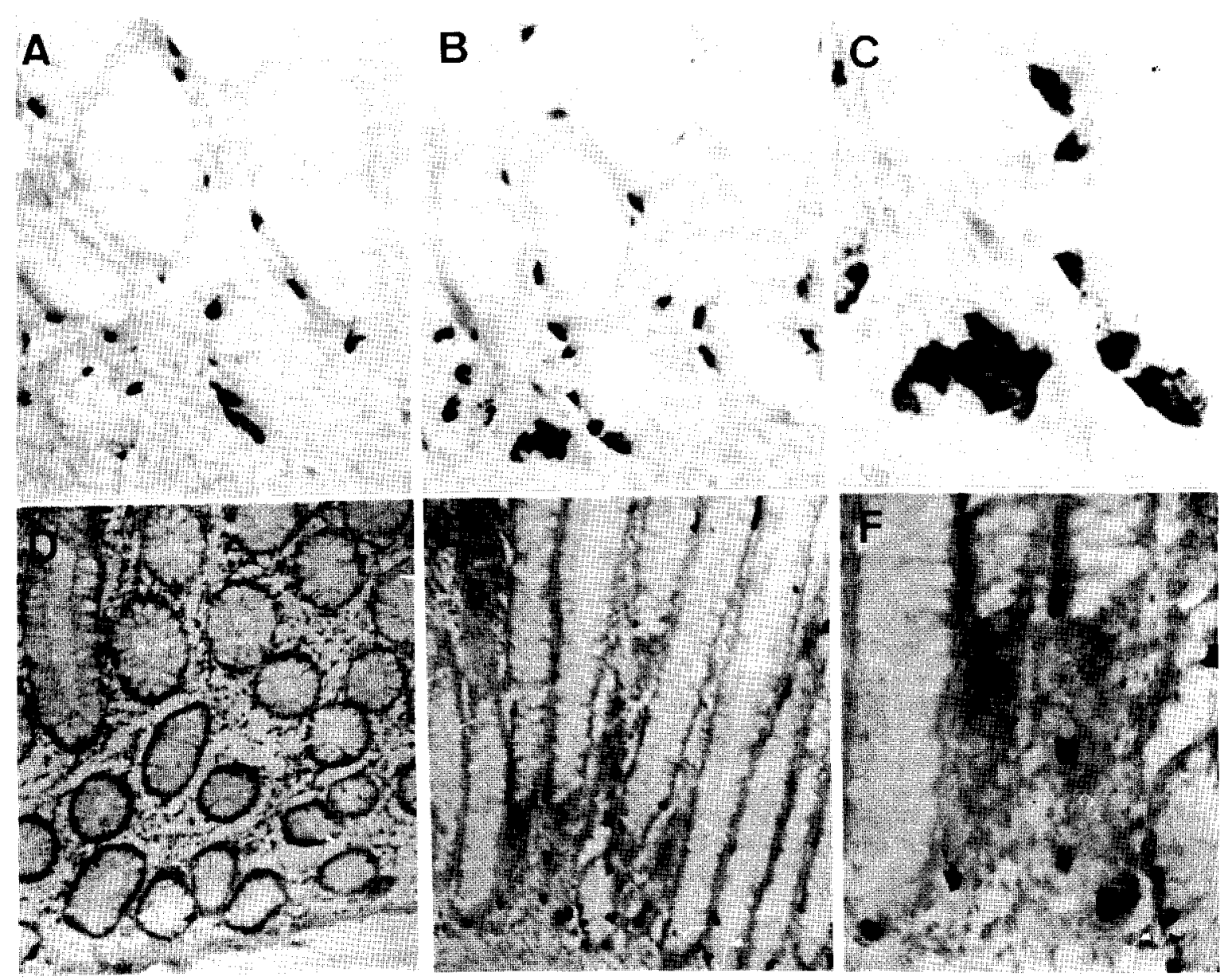

Figura 2-Microfotografias da mucosa de cólons controles ( $A$ e D) e de megacólons chagásicos $(B, C, E$, e $F$ ) coradas para evidenciar células enterocromafins $(E C)$ e células $E C$ mais argirófilas. Observar que nos megacólons as células endócrinas apresentam-se aparentemente mais coradas e mais númerosas ( $C$, detalhe de $B ; F$, detalhe de $E)$. $(A, B$, $C$, coloração pelo método de Masson-Fontana modificado, $A$ e $B 180 x ; C, 500 x ; D, E$ e $F$, coloração pelo método de Sevier-Munger, $D$ e $E, 80 x$ e $F, 180 x$ ).

hipotrofia da parede. Entretanto, onde não atuam estes fatores secundários, a parede do megacólon encontrase espessada e os resultados do presente trabalho mostram que não somente as camadas musculares são responsáveis por esse espessamento mas também a mucosa. Como não se observaram lesões anatômicas ao nivel da mucosa nos casos estudados, a não ser em alguns, a presença de infiltrado inflamatório moderado na lâmina própria (também observado em controles) é licito sugerir que, pelo menos em parte, o aumento da espessura da mucosa se deve ao aumento da massa do componente epitelial da mesma. Sendo dificil imaginar uma relação direta entre essas modificações quantitativas das glândulas colônicas e a lesão ao nivel dos plexos intramurais que ocorre no megacólon é possivel que esta "hipertrofia glandular" seja o resultad de adaptação da mucosa às novas dimensões do órgào.
O aumento da espessura da camada muscular, de intensidade variável, é achado comum nas enteromegalias chagásicas ressalvadas os casos de alterações secundárias que podem acarretar o adelgaçamento da mesma, como explicado anteriormente. As alterações responsáveis pelo espessamento da muscular já são em grande parte conhecidas sendo principalmente: hipertrofia de fibrocélulas musculares, miosite e periganglionite com ou sem fibrose correspondente e fibrilopoese difusa e sistematizada não relacionada diretamente com os focos inflamatórios 35

Não se encontra, na literatura, estudo das células EC no megacólon chagásico. Estas células estão presentes na mucosa do tubo digestivo em grande número. Constituem fonte de produção de peptideos com acões biológicas diversas sobre a musculatura lisa ${ }^{2} 1828$ e de 5-HT que apresenta ações tanto sobre 
a musculatura intestinal como sobre a parede vascular $^{6} 11$. No intestino, a concentração de 5-HT no tecido é correlata com a população de células $\mathrm{EC}^{29}$ e esta amina, ou seus precursores, podem ser encontrados tanto em neurónios como em terminações nervosas de mamiferos, inclusive do homem ${ }^{8}$. Embora atualmente a demonstração de células EC possa ser feita imunocitoquimicamente ${ }^{9} 19$ o método da reação argentafim ainda continua sendo um dos mais usados e confiaveis ${ }^{17}$. Utilizando esta técnica, estas células foram facilmente demonstradas em nosso material. Embora a impressão inicial fosse de que estivessem aumentadas na maioria dos casos de megacólon, a contagem sistematizada, por campo e por cripta, não resultou em média significativamente diferente daquela dos controles. É possivel, portanto, que essas células não estejam aumentadas numericamente no megacólon chagásico, ao contrário do observado por Lindop 25 em um caso de megacólon idiopático. Dados da literatura mostram evidèncias de que as células EC apresentam baixa capacidade de renovação em relação às demais células de função exócrina da mucosa colônica 39 . Por outro lado, não se pode excluir uma possivel hipertrofia dessas celulas nos megacólons, uma vez que pareceram relativamente maiores e mais bem coradas. A redução da prata pelas células EC, reação responsável pela sua coloração, ocorre a nivel de seus grânulos de secreção ${ }^{34}$ com a possivel participação de produto que deriva de seu conteúdo aminérgico com o grupo aldeído do fixador 17 . Portanto, células EC pouco granulares, ou pobres em secreção, não se coram ou se coram pouco, enquanto que células EC ricas em secreção coram-se mais intensamente. Portanto, um possivel mecanismo de hipertrofia de células EC poderia ser o responsável pelo seu aparente aumento numérico ou impregnação mais forte pela prata, como foi observada na maioria dos casos do megacólon chagásico. Estudos à microscopia eletrônica poderiam confirmar ou afastar a hipertrofia celular e métodos imunocitoquímicos se fazem necessários para esclarecer se peptideos, presentes nestas células, estariam sofrendo estimulo hipersecretório.

O método de Servier-Munger, por sua vez, além das células EC cora um determinado número de células endócrinas ainda não totalmente conhecidas. No pâncreas, as células A (glucagon) e as PP (peptideo pancreático) são positivas enquanto que as $\mathrm{D}$ (somatostatina) e as B (insulina) são negativas 40 . No tubo digestivo de mamiferos, inclusive humano, as células "enterocromafin-like", as células K, produtoras de peptídeo inibidor gástrico, as células Dl (produto desconhecido) além de outros tipos, ainda não bem identificados, são evidenciados pela reação de Sevier-Munger 48 . No cólon humano, através de métodos imunocitoquímicos e ultra-estruturais, além das células EC que perfazem $50 \%$ ou mais da população endócrina deste órgão, são também encontradas: $(a)$ : células contendo substâncias $\mathbf{P}$, provavelmente em uma fração das células $\mathrm{EC}:(b)$ : células
L, produtoras de enteroglucagon ou glicentina; $(c)$ : células $\mathrm{D}$, produtoras de somatostatina; $(d)$ : células "F-like" ou "PP-like" que podem reagir com determinados anti-soros contra peptídeo pancreático e $(e)$ : outros tipos mais raros nem sempre detectados na mucosa colônica, como as células $\mathrm{N}$, produtoras de neurotensina, e as células $\mathrm{P}$ e $\mathrm{H}$ de função desconhecida $^{5} 31$. Além disso, a coexistência na mesma célula de diferentes peptideos tem sido freqüentemente relatada. Recentemente caracterizou-se um novo peptídeo presente em células endócrinas, com mesmo número e seqüência de aminoácidos do peptídeo pancreático e que seria o responsável pela evidenciação imunocitoquímica de células "PP-like" na mucosa colônica 37 . Dados atuais da literatura indicam que este peptídeo, chamado "peptideo YY" (PYY) está localizado nas células $\mathrm{L}$ coexistindo com enteroglucagon ou glicentinal 17 .

Os resultados do presente trabalho demonstram que as células endócrinas da mucosa colônica, principalmente as células argirófilas, ou uma determinada fração delas, podem estar envolvidas, direta ou indiretamente, nos mecanismos fisiopatológicos ou patogenéticos do megacólon. Uma delas poderia ser as células $\mathrm{L}$, produtoras do $\mathrm{EG}$, uma vez que esta substância parece ter função trófica sobre a mucosa colônica, estimulando a sintese de DNA 20 . Entretanto, são necessários estudos imunocitoquímicos especificos destas diferentes células endócrinas para se avaliar a importância da participação de cada uma delas neste tipo de enteromegalia.

\section{$S U M M A R Y$}

Silver stainings (Masson-Fontana and SevierMunger methods) were applied to sections from surgical specimens of chagasic megasigmoid. The distribution and the number of both enterochromaffin (EC) cells and EC plus argyrophyl (ARG) cells were studied. Both of them, EC and ARG cells presented a predominantly basal localization in mucosal glands of megasigmoids $(n=16)$ and controls $(n=8)$. The counting of $E C$ cells and $E C$ plus $A R G$ cells has shown that only the group EC plus $A R G$ cells was significantly increased. Morphometric studies revealed a significant increase in the thickness of the muscle and mucosa layers of the megasigmoid when compared to the controls.

Key words: Chagasic megacolon. Enterochromaffin cells. Argyrophyl cells. Neuroendocrine cells.

\section{REFERENCIAS BIBLIOGRÁFICAS}

1. Ali-Rachedi A, Varndell IM, Adrian TE, Gapp DA, Van Nooden S, Bloom SR. Polak JM. Peptide YY (PYY) immunoreactivity is co-stored with glucagon-related immunoreactants in endocrine cells of the gut and pancreas. Histochemistry 80: 487-491, 1984.

2. Alumets J, Häkanson R, Sundler F, Chang KJ. LeuEnkephalin-like material in nerves and enterochromaffin cells in the gut. Histochemistry 56: 187-196, 1978. 
3. Barbosa AJA, Castro, LPF, Nogueira AMMF. A simple and economical modification of the Masson-Fontana method for staining melanin granules and enterochromaffin cells. Stain Technology 59: 193-196, 1984.

4. Buffa R, Polak JM, Pearse AGE, Solcia E, Grimelius L, Capella C. Identification of the intestinal cell storing gastric inhibitory peptide. Histochemistry $43: 249-255$, 1975.

5. Buffa R, Capella C, Fontana P, Usellini L, Solcia E. Types of endocrine cells in the human colon and rectum. Cell Tissue Research 192: 227-240, 1978.

6. Bülbring $E$, Lin RCY. The effect of intraluminal application of 5-hydroxytryptamine and 5-hydroxytryptophan on peristalsis; the local production of 5-HT and its release in relation to intraluminal pressure and propulsive activity. Journal of Physiology (London) 140: 381-407, 1958.

7. Böttcher G, Sjölund K, Ekblad E, Hakanson R, Schwartz TW, Sundler F. Coexistence of peptide YY and glicetin immunoreactivity in endocrine cells of the gut. Regulatory Peptides 8: 261-266, 1984.

8. Costa M, Furness JB, Coelho AC, Verhofstad AAJ, Steinbusch HWJ, Elde RP. Neurons with 5-hydroxytryptamine like immunoreactivity in the enteric nervous system: their visualization and reactions to drug treatment. Neuroscience 2: 351-363, 1982.

9. Facer P, Polak JM, Jaffe BM, Pearse AGE. Immunocytochemical demonstration of 5-hydroxytyptamine in gastrointestinal endocrine cells. Histochemical Journal 11: 117-121, 1979.

10. Fahrenkrug J. Vasoactive Intestinal Polypeptide: measurement, distribution and putative neurotransmitter function. Digestion 19: 149-169, 1979.

11. Fath S, Hedlund H, Hultén L, Nordgren S, Oresland T. The effects of 5-hydroxytryptamine on large intestinal motility and blood flow in the cat. Acta Physiologica Scandinavica 118: 329-336, 1983.

12. Fetissof F, Desbois MP, Assan R, Arbeille-Brassart, Baraudi A, Tharanne MJ, Jobard P. Endocrine cells in the anal canal. Virchows Archives (Pathological Anatomy and Histopathology) 404: 39-47, 1984.

13. Ferri G-L, Adrian TE, Mohammad AG, O'Shaughnessy DJ, Probert L, Lee YC, Buchan AMJ, Polak JM, Bloom $\mathrm{SR}$. Tissue localization and relative distribution of regulatory peptides in separated layers from the human bowel. Gastroenterology 84: 777-786, 1983.

14. Fontana A. Verfahren zur intensiven und raschen Farbung des Treponema pallidum und anderer Spirochäten. Dermatologische Wochenschrift. 55: 1003 1004, 1912.

15. Fujita T, Kobayashi S. Paraneural cells in GEP endocrine system. In: Bloom SR (ed.) Gut Hormones, 1st ed. Churchill Livingstone, London, p. 414-422, 1978.

16. Furners JB, Costa $M$. Types of nerves in the enteric nervous system. Neuroscience 5: 1-20, 1980.

17. Grimelius L, Wilander E. Silver stains in the study of endocrine cells of the gut and pancreas. Investigative Cell Pathology 3: 3-12, 1980.

18. Heitz PU, Kasper M, Krey G, Polak JM, Pearse AGE. Immunoelectron cytochemical localization of motilin in human duodenal enterochromaffin cells. Gastroenterology 74: 713-717, 1978.

19. Inokuchi H, Kawai K, Takeuchi Y, Sano Y. Immunohistochemical demonstration of EC cells in rat gastrointestinal tract. Histochemistry 74: 453-456, 1983.
20. Johnson CR. New aspects of the trophic action of gastrointestinal hormones. Gastroenterology 72: 788$792,1977$.

21. Köberle, F. Megacolon. Journal of Tropical Medicine and Hygiene 61: 21-24, 1958.

22. Köberle, F. Patogenia do megaesôfago brasileiro e europeu. Revista Goiana de Medicina 9: 79-116, 1963.

23. Kurian SS, Ferri G-L, De Mey J, Polak JM. Immunocytochemistry of serotonin-containing nerves in the human gut. Histochemistry 78: 523-529, 1983.

24. Larsson LI, Goltermann N, De Magistries L, Rehfeld JF, Schwartz TW. Somatostatin cell processes as pathways for paracrine secretion. Science 205: 13931395, 1979.

25. Lindop GBM. Enterochromaffin cell hyperplasia and megacolon: report of a case. Gut 24: 575-578, 1983.

26. Long RG, Bishop AE, Barnes AJ, Albuquerque RH, O'Shaughnessy DJ, McGregor GP, Bannister R, Polak JM, Bloom SR. Neural and hormonal peptides in rectal biopsy specimens from patients with Chagas' disease and chronic autonomic failure. Lancet 1: 559-562, 1980.

27. Masson MP. La glande endocrine de l'intestin chez l'homme. Comptes Rendus Hebdomadaires des Séances de l'Academic des Sciences 158: 59-61, 1914.

28. Pearse AGE, Polak JM. Immunocytochemical localization of substance $\mathrm{P}$ in mammalian intestine. Histochemistry $41: 373-375,1975$.

29. Resmick RH. Gray SJ. Distribution of serotonin (5hydroxytryptamine) in the human gastrointestinal tract. Gastroenterology 41: 119-121, 1961.

30. Sevier AC, Munger BL. A silver method for paraffin sections of neural tissue. Journal of Neuropathology and Experimental Neurology 24: 130-135, 1965.

31. Sjölund K, Sandén G, Hakanson R, Sundler F. Endocrine cells in human intestine: an immunocytochemical study. Gastroenterology 85: 1120-1130, 1983.

32. Solcia E, Polak JM, Larsson, L-I, Buchan AMJ, Capella C. Update on Lausanne classification of endocrine cells. In: Bloom SR, Polak JM. (eds.) Gut Hormones. 2nd ed. Churchill Livingstone, London, p. 98-100, 1981.

33. Solcia E, Capella C, Buffa R, Frigerio B, Usellini L, Fiocca R. Morphological and functional classification of endocrine cells and related growths in the gastrointestinal tract. In: Class GBJ (ed.) Gastrointestinal Hormones, Raven Press, New York, p. 1-17, 1980.

34. Solcia E, Capella C, Buffa RE, Usellini L, Fiocca R, Frigerio $B$, Tenti $P$, Sessa $F$. The diffuse endocrine paracrine system of the gut in health and disease: Ultrastructural features. In: Polak JM, Bloom SR, Wright NA, Daly MJ (ed.) Structure of the gut. Glaxo Group Research Ltd. Ware, Herts, UK, 1982.

35. Tafuri WL, Maria TA, Lopes ER. Alteraçōes das células e dos componentes do interstício no megaesôfago na tripanosomíase cruzi humana. Estudo ao microscópio eletrônico. Revista da Associação Médica de Minas Gerais. 24: 1-24, 1973.

36. Tafuri, WL. Doença de Chagas. Anais do Instituto de Ciências Exatas e Biológicas da Universidade Federal de Ouro Preto 1: 118-150, 1983.

37. Tatemoto $K$. Isolation and characterization of peptide YY (PYY), a candidate gut hormone that inhibits pancreatic exocrine secretion. Proceedings of National Academy of Sciences USA 79: 2514-2518, 1982.

38. Vassalo G, Capella C, Solcia E. Endocrine cells of the human gastric mucosa. Zeitschrift für Zellforschung und Mikroskopische Anatomie 118: 49-67, 1971. 
Barbosa AJA, Toppa NH, Melo JRC, Tafuri WL. Alteraçōes quantitativas das células neuroendócrinas no megacólon chagásico. Revista da Sociedade Brasileira de Medicina Tropical 18: 215-221, Out-Dez, 1985

39. Verity MA, Mellinkoff SM, Frankland M, Greipel M. Serotonin content and argentaffin and Paneth cell changes in ulcerative colitis. Gastroenterology 43: 24$31,1962$.
40. Willander E, Lundqvist M, Westermark P, Grimelius L. Immunocytochemical study of argyrophil (Sevier Munger) endocrine cells of adult human pancreas. Histochemistry 68: 95-98, 1980. 